\title{
RABELO, Miriam C.M. 2014. Enredos, Feituras e Modos de Cuidado. Dimensões da Vida e da Convivência no Candomblé. Salvador: EDUFBA. 296 p.
}

Alline Torres Dias da Cruz (Colégio Pedro II)
Miriam Rabelo nos convida, com seu livro, a compartilhar existências e cotidianos "sensíveis e significativos" (:129), entremeados pelos seres e agências do "mundo do candomblé" (: 22-23). Aceitar este convite é engajar-se com uma experiência narrativa na qual se revê o processo de criação de vínculos entre os humanos e as diversas entidades desta religião. Da extensa bibliografia que se dedicou a este problema clássico dos estudos antropológicos sobre as religiões de matriz africana no Brasil encontram-se os textos de Roger Bastide, Pierre Verger, Gisele Cossard, Juana Santos, Márcio Goldman, Ligia Segato, Reginaldo Prandi e Roger Sansi-Roca.

Como eles, Miriam Rabelo também lida com materiais de campo, que foram produzidos entre 1998 e 2013 em um terreiro de candomblé, o llê Axé Alá Key Koysan, localizado na cidade de Salvador e liderado por Mãe Beata, iyalorixá e zeladora da casa. Mas a ideia de revisão soa insuficiente para dar conta da densidade etnográfica e singularidade analítica do livro. Resultado, principalmente, de seu envolvimento, inclusive como adepta, naquele terreiro, a obra conecta dados etnográficos eminentemente sensoriais e dinâmicos sobre os encontros entre pessoas, orixás, exus, erês e caboclos ao diálogo com autores como Merleau-Ponty, Michael Lambek, Tim Ingold e Bruno Latour.

Sua etnografia apresenta ao leitor os modos de convivência e cuidado que possibilitam tanto a manutenção ritual das entidades quanto a transformação de espíritos, deuses e adeptos. Informada pelo pressuposto fenomenológico merleau-pontiano de que ideias e sensibilidades se articulam, a autora enfatiza os procedimentos e práticas religiosos para discutir o aprendizado e a ética no candomblé ao longo do livro. Para chegar ao aprendizado religioso a autora mapeia, antes, os caminhos de uma empreitada que ocorre muitas vezes fora dos terreiros nos quais a ligação ritual ocorre.

Com "Percursos", Rabelo dá início ao livro. Salienta a importância que a Campos 15(2):177-180, 2014 circulação pelos bairros populares ocupou nas narrativas dos interlocutores sobre as 
situações e eventos que lhes indicavam algum tipo de vínculo com espíritos e deuses. Chegar a um terreiro, a autora destaca, significa levar consigo o "peso de uma história" e manter para si um "horizonte aberto" (:31). Além disso, indica que a socialização religiosa de seus interlocutores teve início na infância. O trânsito pelas casas de candomblé - das quais algum familiar participava como iniciado na religião ou eram dirigidas por vizinhos - e, ainda, por sessões espíritas domésticas, dá relevo aos bairros populares como ambientes em que foi estabelecida alguma convivência com experiências afrorreligiosas.Mas Rabelo é cuidadosa sobre os efeitos advindos da afirmação de que os bairros populares soteropolitanos são uma espécie de "ambiência" (: 64) para a socialização no candomblé. Tomando os percursos de Dona Detinha nesta religião (interlocutora de quase 80 anos em fins dos anos 1990), a autora sinaliza para uma concepção de trajetória que não é linear, tampouco uniforme. Destaca, também, que para compreender os movimentos de Dona Detinha em direção ao candomblé não basta localizá-los nos bairros populares de Salvador. Aliados a estes espaços, havia o tempo dos percursos e tudo aquilo que Dona Detinha aprendeu com a passagem dele.

Para a autora, a trajetória religiosa desta interlocutora se caracteriza por um "movimento constante e incerto" (:76), que se constitui de vacilações, paradas e retomadas com intensidades diferenciadas, no trânsito entre casa e terreiro e de um terreiro a outro. Este "horizonte aberto", que outros interlocutores também experienciaram antes de se vincular ritualmente a um terreiro (e que permanece como possibilidade em caso de rompimento com o terreiro em que a iniciação ritual foi realizada), constitui uma vivência da qual faz parte também um movimento de regresso. Após frequentes hesitações e desvios, a iniciação no candomblé significa retornar a um vínculo com as entidades que existia antes da "feitura do santo" (: 81).

Este retorno ontológico é uma decisão cara aos adeptos. No início de "Histórias e feituras", Rabelo salienta mais do que os custos econômicos da iniciação ritual. Dá atenção às implicações pessoais que são criadas pelo cultivo dos vínculos com as entidades do candomblé. Implicações que explicam o porquê de muitos dos interlocutores retardarem ou interromperem, ainda que temporariamente, a aproximação de deuses e espíritos. Esse foi caso de Mãe Beta, cujo pai, adepto da religião, "suspendeu" o santo da filha ainda criança (: 36$)$.

Na narrativa etnográfica sobre o aprendizado religioso, ser feito no candomblé é "instituir" (: 92) uma relação em que a mãe de santo é tão fundamental quanto os outros mediadores que fazem parte do terreiro. No entanto, a iniciação ensina à iaô que aprender no candomblé significa saber "sujeitar-se" (: 111). Para Rabelo, isto se deve aos modos como o conhecimento é acessado e circula dentro dos terreiros. Para as mães e os pais de santo, limitar o acesso ao conhecimento religioso significa uma proteção ritual. Aqueles que não estão prontos para lidar com as energias ativadas pelos adeptos mais experientes devem saber menos. Entretanto, para a autora, essa proteção não se associa somente à hierarquia religiosa, ou seja, não deveria ser entendida como um processo natural no qual o adepto acumula conhecimento.

Rabelo observa que se pelo menos idealmente a autoridade e o conhecimento são controlados pelas próprias entidades ou por aqueles que têm mais tempo de feitura - e isso inclui a iniciação e as obrigações que devem ser feitas em períodos de 3, 5 e 7 anos até a mudança de status religioso da iaô -, saber menos no candomblé significa 
mais do que não estar ainda ritualmente preparado. Trata-se de uma questão ontológica, “[...] é menos problema de conhecimento do que questão de ser (: 106; 111)". Seu argumento é o de que o aprendizado no candomblé evidencia a maneira como uma pessoa deve ser feita na religião. Os mais velhos na hierarquia religiosa investem na produção da falta de conhecimentos dos iniciados. De modo que aprender no candomblé é produzir a(o) iaô como alguém que precisa vivenciar o desconhecimento ritual e a performance da submissão no cotidiano do terreiro.

Se as pessoas aprendem, o mesmo ocorre com as entidades. Também faz parte do cotidiano de um terreiro "educar" (: 118) ou "doutrinar" (: 120) orixás, caboclos, exus e erês, introduzindo-os ao convívio com o iniciado, os adeptos e o espaço religioso. Os modos de aprendizado das entidades demonstram a importância de mobilizar a sua força para difundi-la no terreiro e das práticas que buscam fixá-las nele. Por isso, a autora concebe o aprendizado no candomblé como um "modo de cultivo" (: 124) do qual tomam parte inúmeros seres e agências no interior de um terreiro, em situações caracterizadas pela incerteza e pelo risco.

E é para a relação entre o filho de santo e seu orixá, descrita da perspectiva das situações e dos procedimentos que compõem os diversos percursos que culminam na feitura do santo, que a autora volta sua atenção em “Movimento: rodar com o santo". Rabelo recoloca a questão do aprendizado no candomblé. O filho de santo aprende a desenvolver no terreiro "não [...] tanto a habilidade da possessão, mas a relação com o santo" (: 140). Ainda que os rodantes desenvolvam habilidades específicas ("técnicas"), o que importa na iniciação é aprender a reconhecer e lidar com o orixá que, inicialmente, é uma força muito sensível, porém pouco significativa. Em contrapartida, a mãe de santo tem a tarefa de assegurar que o orixá se forme como alteridade que se vincula ao corpo e, ao mesmo tempo, se torne relativamente autônomo do filho de santo. Assim, é importante no processo de feitura não apenas a mediação dela, mas também a do terreiro (de paisagens, coisas, substâncias, cantos, animais, vegetais e seres humanos). Rabelo observa que, para os iniciados, a mediação de ambos (mãe de santo e terreiro) funciona como uma nova ambiência que cria as condições para a transformação ritual da iaô, que se submete ao orixá e à hierarquia do candomblé. E salienta: para a(o) rodante de modo geral, iniciado ou não, a presença do santo lhe chega como movimento - deslocamentos espaço-temporais cujas qualidades são diferenciadas, e, que, lentamente, configuram um estilo para o adepto.

Se dentro da hierarquia religiosa espera-se que a experiência de rodar com o santo possa ser regulada e estabilizada durante o aprendizado religioso, a iniciação e os períodos de cumprimento das obrigações configuramse como procedimentos que marcam a submissão e a perda de agência para o orixá. Essas são algumas das difíceis implicações da feitura. Os adeptos as descrevem como um gasto de energia, uma forma de passividade e falta de comando sobre si. Para a autora, se trata da "suspensão da agência" (: 177). Tal consequência, que faz parte das experiências iniciais (anteriores ou ao longo dos anos de iniciação ritual) de "rodar com o santo", passam a assumir outra configuração à medida que o santo e a pessoa são produzidos e fortalecidos no terreiro. Com o convívio, o conhecimento e a intimidade, ocorrem alterações nas dinâmicas relacionais entre filho de santo e entidade. "Rodar com o santo" continua dependendo do "entorno" e do "contexto" (: 143).

Porém uma etiqueta, que resulta da iniciação ritual, da educação do santo e da intervenção dos mediadores (mãe de santo e membros experientes do terreiro), diminui a frequência e a intensidade da presença corporal das 
entidades junto ao rodante. Quando chama a atenção para essas dimensões relacionais do aprendizado religioso, Rabelo descentra sua narrativa e produz outra imagem do candomblé. Não se trata de enfatizá-lo como uma tomada abrupta e repentina de espíritos e deuses. O que sobressai é o "tempo do amadurecimento" e também da rotinização da relação com o santo (: 169), aquele que foi tão fundamental nos percursos de Dona Detinha.

Um dos efeitos de "Assentamentos" é deslocar a imagem do candomblé ligada às festas públicas. Atenta às práticas de cuidado cotidiano com as entidades dentro do terreiro, Rabelo relata a produção, a manutenção e a restauração dos vínculos que constituem este espaço religioso a partir do enfoque nos assentamentos. Em diálogo com a teoria ator-rede de Bruno Latour, a autora propõe uma narrativa em que estes fundamentos do candomblé uma composição formada basicamente por pratos, vasos, sopeiras, tigelas e inúmeras substâncias e artefatos - sejam tratados, de fato, como "objetos" (: 198) da investigação nas Ciências Sociais.

No candomblé o orixá se encontra no assentamento. Deste conjunto de objetos rituais emerge seu poder. Logo, cuidar do assentamento é cuidar da entidade. É, ainda, garantir o equilíbrio do adepto, filho de um orixá único que foi fixado no terreiro, e da mãe de santo, responsável pela feitura de ambos. Destra trama relacional emerge uma série de vínculos religiosos que conectam (e desconectam em casos de assentamentos abandonados ou desfeitos) entidades, coisas e pessoas continuamente, uma vez que todos são transformados e refeitos a cada obrigação cumprida, a cada trabalho ritual solicitado à mãe de santo. Para a autora, os assentamentos instituem um lugar no terreiro no qual se juntam e se fazem mãe de santo, filho de santo e orixá.

Os assentamentos promovem as circunstâncias para que vários eventos e situações ocorram no terreiro, desde que foram "instituídos" como lugar para a performance da sujeição. Neste sentido, estes conjuntos posicionam o corpo dos adeptos, orientam seus movimentos e ações para que sejam promovidos os encontros entre pessoas e entidades. Mas para a autora isso não é tudo. Se os assentamentos estabelecem diversos vínculos religiosos e garantem a manutenção deles, também dependem das intervenções humanas que cuidadosamente transformam o espaço - nas palavras da autora, o "chão", do qual os assentamentos se alimentam e no qual se desenvolvem (: 205-207). Grande parte destas intervenções se refere à circulação (e preparação) de comida. Ao descrever um bori (do qual ela mesma participou), Rabelo ressalta que seguir os "percursos da comida e (do repouso) no terreiro" traz à discussão uma intricada dinâmica de cuidado com as entidades, mas também com os iniciados. Em contraste com todos os movimentos que se realçam nas festas públicas, durante a iniciação os ritos que selam e fortalecem o vínculo religioso se fundam na produção e distribuição de alimentos. Estes dois momentos possuem ritmos de engajamento, duração e tempo de consumo e transformação muito próprios. Apoiando-se nos aspectos cotidianos e matizados da construção da pessoa, especialmente nos ritos do bori, a autora sugere que o candomblé solicita de seus adeptos uma atenção estética da qual faz parte uma ética. Para Rabelo, o comprometimento com as entidades - aprender a reconhecê-las e com elas se relacionar - não se separa da formação de uma sensibilidade.

Recebido em: 01/06/2015

Alline Torres Dias da Cruz é Doutora em Antropologia Social pelo Aprovado em: 04/09/2015 